\title{
DETERMINATION OF THE LIFE SPAN OF HUMAN BLOOD PLATELETS USING LABELLED DIISOPROPYLFLUOROPHOSPHONATE
}

\author{
By C. H. W. LEEKSMA AND J. A. COHEN \\ (From the Department of Metabolic Diseases, University of Leyden and the Med. Biol. Lab. \\ of the National Defense Research Council, T.N.O., Rijswijk, Holland)
}

(Submitted for publication January 20, 1956; accepted May 10, 1956)

Recently we have reported a method for the determination of platelet survival time using diisopropylfluorophosphonate (DFP) as the labelling agent (1). The present communication presents full details of this method.

Hitherto, no satisfactory method for the determination of platelet survival time has been described. Most data on this subject have been obtained by means of transfusion experiments (2-5). In these experiments the survival time of platelets is determined after transfusion of blood or platelet concentrates of normal and polycythemic donors into patients with aplastic anemia and other diseases where this determination was possible because of absence or morphological differences of the platelets of the recipient. In most cases a survival time of 3 to 6 days has been found. In some cases however a small part of the transfused platelets is found to be present in the circulation of the recipient 7 to 8 days after transfusion $(5,6)$. However, the results obtained in these studies are subject to considerable criticism since the platelets are damaged during the process of blood collection, concentration, and transfusion. The survival time of platelets is therefore partly determined by the technique used (4). Though several investigators have attempted to label platelets with radioactive isotopes (7-14), no technique has been provided that can be considered satisfactory with regard to the determination of survival time.

In a previous communication, Cohen and Warringa (15) reported the use of $\mathrm{P}^{32}$ labelled diisopropylfluorophosphonate $\left(\mathrm{DFP}^{32}\right)$ in the determination of the life span of erythrocytes. This method is based on the irreversible combination of $\mathrm{DFP}^{82}$ with esterases present in the red cell membrane. A mean red cell life span of 116 and 129 days, respectively, was found in two normal subjects. These values are in accordance with those reported in the literature.
Since thrombocytes have also been shown to contain esterases (16) the same method suggested itself as a way of measuring the life span of these cells. It seemed reasonable to assume that conditions similar to those described for red cells would obtain; viz., that the reaction of $\mathrm{DFP}^{82}$ with the proteins of platelets would be irreversible and that metabolites of $\mathrm{DFP}^{32}$ would be liberated only with the ultimate destruction of labelled cells. Shortly after the administration of DFP ${ }^{32}$ the DFP sensitive enzymes combine irreversibly and DFP is not linked to newly formed proteins since active DFP is not available. DFP administered intramuscularly is absorbed rapidly, and disappears from the circulation within a short period. Moreover the metabolites of DFP have been shown not to be incorporated in newly formed proteins.

\section{METHODS}

The labelled diisopropylfluorophosphonate (DFP used was synthetized by $R$. A. Oosterbaan by a method which has been previously reported (17). DFP was administered intramuscularly in oil as described in an earlier report (15). Measurements of platelet-bound radioactivity were made at various intervals after the injection of the DFP'2 These studies were conducted on 5 patients without hematologic abnormalities (A, B, C, D, and $G$ ), three patients with polycythemia vera ( $F, M$, and $N)$ one patient with chronic myeloid leukemia (E), two postoperative patients ( $\mathrm{H}$ and $\mathrm{I}$ ), one patient with persistent thrombocytosis following splenectomy (K) and one patient with thrombocytopenic purpura (L) who had a remission following ACTH treatment. Data on these patients, the dose of DFP and the amount of radioactivity administered are presented in Table I.

Isolation of platelets. Forty-five to fifty-ml. blood samples are drawn from the antecubital vein into a siliconized tube and mixed with $5 \mathrm{ml}$. 1 per cent sodium ethylenediamine tetra-acetate in 0.9 per cent sodium chloride. The blood is transferred into siliconized centrifuge tubes and spun for ten minutes applying a force of $80 \mathrm{G}$. The supernatant platelet-rich plasma is removed with a siliconized pipette. Generally not all of the plasma can be removed without disturbing the buffy coat; hence a constant loss of about 15 per cent of the plasma volume 
TABLE I

Data on patients to whom DFPe was administered

\begin{tabular}{|c|c|c|c|c|c|c|}
\hline Patient & Age & Sex & Clinical diagnosis & $\begin{array}{c}\text { Body } \\
\text { weight }\end{array}$ & \multicolumn{2}{|c|}{ Dose DFPy } \\
\hline $\begin{array}{l}\text { A } \\
\text { B } \\
\text { C } \\
\text { D } \\
\text { E }\end{array}$ & $\begin{array}{l}y r s . \\
68 \\
17 \\
71 \\
49 \\
66\end{array}$ & $\begin{array}{l}\mathbf{M} \\
\mathbf{M} \\
\mathbf{M} \\
\mathbf{M}\end{array}$ & $\begin{array}{l}\text { Healed thrombosis } \\
\text { Duodenal ulcer } \\
\text { Asthma } \\
\text { Duodenal ulcer } \\
\text { Chronic myeloid leukemia, thrombocy- }\end{array}$ & $\begin{array}{l}k g . \\
70 \\
71 \\
66 \\
75\end{array}$ & $\begin{array}{l}m g . \\
0.515 \\
0.654 \\
1.37 \\
0.411\end{array}$ & $\begin{array}{r}\mu c . \\
90 \\
61 \\
107 \\
40\end{array}$ \\
\hline $\begin{array}{l}\mathbf{F} \\
\mathbf{G} \\
\mathbf{H} \\
\mathbf{I}\end{array}$ & $\begin{array}{l}59 \\
69 \\
57 \\
49\end{array}$ & $\begin{array}{l}\mathbf{M} \\
\mathbf{F} \\
\mathbf{M}\end{array}$ & $\begin{array}{l}\text { tosis } \\
\text { Polycythemia vera thrombocytosis } \\
\text { Apoplexy } \\
8 \text { days after cholecystectomy } \\
8 \text { days after nailing operation for frac- }\end{array}$ & $\begin{array}{l}39 \\
91 \\
85 \\
80\end{array}$ & $\begin{array}{l}0.63 \\
1.37 \\
1.09 \\
1.2\end{array}$ & $\begin{array}{r}102 \\
124 \\
70 \\
150\end{array}$ \\
\hline $\begin{array}{l}\text { K } \\
\mathbf{L}\end{array}$ & $\begin{array}{l}47 \\
63\end{array}$ & $\mathbf{M}$ & $\begin{array}{l}\text { ture of the femur head } \\
\text { Thrombocytosis after splenectomy } \\
\text { Thrombocytopenic purpura due to gold }\end{array}$ & $\begin{array}{l}69 \\
69\end{array}$ & $\begin{array}{l}1.0 \\
1.17\end{array}$ & $\begin{array}{l}130 \\
145\end{array}$ \\
\hline $\mathbf{M}$ & 51 & $\mathbf{M}$ & $\begin{array}{l}\text { in remission after ACTH therapy } \\
\text { Polycythemia vera splenomegaly low }\end{array}$ & 47 & 1.1 & 140 \\
\hline $\mathrm{N}$ & 77 & $\mathbf{M}$ & $\begin{array}{l}\text { platelet count } \\
\text { Polycythemia vera splenomegaly low } \\
\text { platelet count }\end{array}$ & 71 & $\begin{array}{l}0.92 \\
0.8\end{array}$ & 110 \\
\hline
\end{tabular}

is encountered. The platelet-rich plasma is centrifuged for 15 minutes applying a force of $220 \mathrm{G}$. Most of the leucocytes and erythrocytes (if present) are then collected on the bottom of the tube, the erythrocytes being clearly visible as a red layer. On the top of this the platelets are already partly sedimented. These are resuspended, every precaution being taken to prevent stirring of the bottom layer. The plasma is pipetted into another tube; it should never contain more than one erythrocyte or leucocyte per 5000 platelets. If too much contamination with other cells is present the separation has to be repeated. In order to isolate more blood platelets from the same blood sample the upper third of the compacted red cells and the portion of the plasma that has not been pipetted off during the first procedure are transferred to another centrifuge tube. By the same procedure of differential centrifugation as described above a second quantity of platelet-rich plasma can be prepared. The plasma thus collected is thoroughly mixed. A small sample is used for the determination of the number of platelets by counting in duplicate, a 3.8 per cent sodium citrate solution being used as diluting agent. At the the same time the number of erythrocytes and leucocytes still present is determined. The total amount of plasma obtained is measured and is centrifuged for 40 minutes applying a force of $2750 \mathrm{G}$. After the supernatant plasma has been discarded the resultant platelet mass is washed three times with saline. If more platelets have to be collected all cell masses left are resuspended in the plasma that has been freed of platelets and the whole procedure is repeated once more. In this way the platelet yield from the same sample can be increased by about 20 per cent. Control estimations of the radioactivity of the washings indicate that the washing procedure does not interfere with the platelet-bound radioactivity.

Measurement of the radioactivity. The platelets are hydrolyzed for 30 minutes at $100^{\circ} \mathrm{C}$. in $3 \mathrm{ml}$. 30 per cent sodium hydroxide. The volume is made up to $10 \mathrm{ml}$. and the radioactivity of this final solution is measured as described before, using a Geiger Müller liquid counter. By relating the measurements to controls obtained by alkaline hydrolysis of labelled diisopropylfluorophospho-

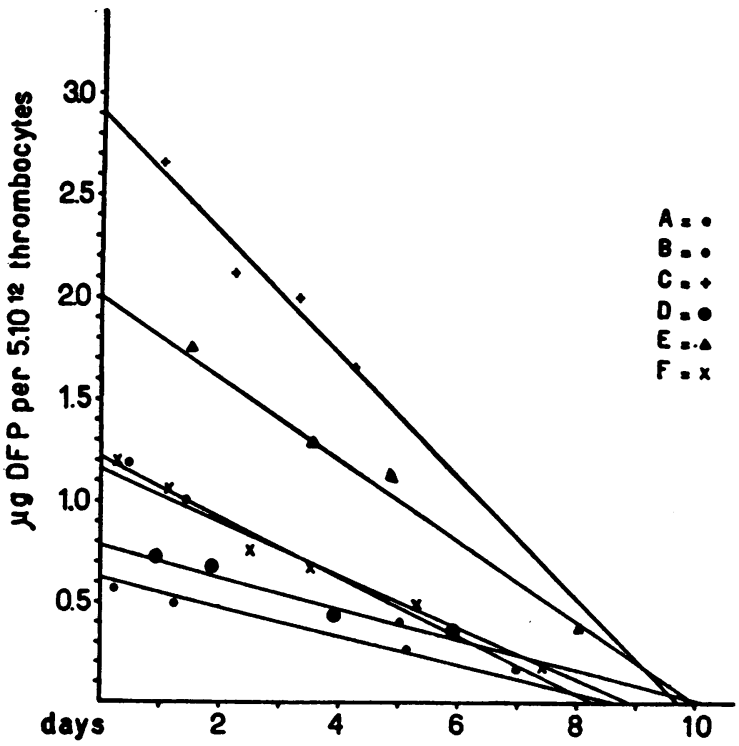

Fig. 1. Platelet-Bound Radioactivity after Injection of DFP

Activity expressed in $\mu \mathrm{g}$. of DFP per $5 \times 10^{23}$ platelets in the blood of subjects A, B, C, D, E, and F. Curves drawn by method of least squares.

A, B, C and D patients without hematologic abnormalities. For details about these patients the reader is referred to Table I.

E female; 66 years; chronic myeloid leukemia, thrombocytosis.

F male; 59 years; polycythemia vera, thrombocytosis. 


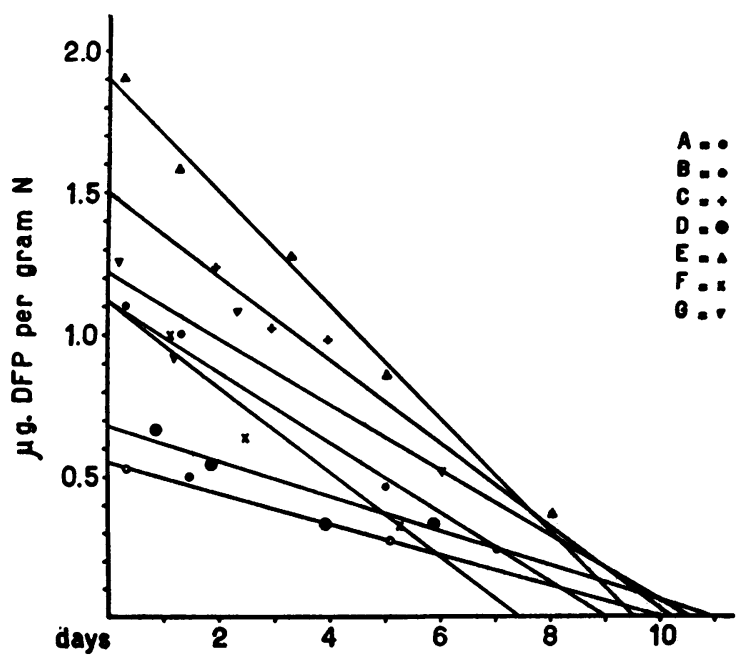

Fig. 2. Platelet-Bound Radioactivity after Injection oF DFP 22

Activity expressed in $\mu \mathrm{g}$. of DFP per Gm. of platelet nitrogen in the blood of subjects $A, B, C, D, E, F$, and G. Curves drawn by method of least squares.

A. B, C, D and G patients without hematologic abnormalities.

For details about these patients the reader is referred to Table I.

E female; 66 years; chronic myeloid leukemia, thrombocytosis.

F male; 59 years; polycythemia vera, thrombocytosis.

nate of known radioactivity, it is possible to determine the diisopropylfluorophosphonate content of the measured samples. The same sample is used for the determination of the nitrogen content (Kjeldahl). Hemolysates are prepared as previously described (15).

The results of the measurements of plateletbound radioactivity in patients $A, B, C, D, E, F$, and $\mathrm{G}$ are presented in Figures 1 and 2. A, B, $\mathrm{C}, \mathrm{D}$ and $\mathrm{G}$ had no hematologic abnormalities. $\mathrm{E}$ and $F$ were suffering from myeloid leukemia and polycythemia vera, respectively (Table I).

The activity is expressed in micrograms DFP per $5 \times 10^{12}$ platelets in Figure 1 and in micrograms DFP per Gm. platelet nitrogen in Figure 2. It was found that $1 \mathrm{Gm}$. platelet nitrogen corresponded with about $5 \times 10^{12}$ platelets. The results do not differ significantly although the variation is somewhat higher where they are expressed per gram nitrogen. Probably this is due to technical difficulties in the determination of platelet nitrogen.

The linear relationship between time and platelet-bound radioactivity indicates that the destruction of platelets is attributable to a limited life span and not to random processes. The slope of the curves obtained suggests that the life span is about 9 days. This figure might possibly be somewhat exaggerated in some cases owing to contamination with radioactivity from other cells. Contamination reveals itself sometimes as a slight residual radioactivity after the ninth day. Since labelled thrombocytes disappear more rapidly from the circulation as a result of their shorter life span, the interference of contaminating red cells increases with time. However the error in the calculation as a result of contamination with other cells is no more than one day at most. The normal life span of the platelets can therefore be estimated as 8 to 9 days. Determination of the amount of $\mathrm{DFP}^{32}$ bound to leucocytes after isolation of these cells from the peripheral blood showed a high uptake 6 hours after injection with $\mathrm{DFP}^{32}$. However, in leucocytes isolated one or more days after injection all, or nearly all, activity had disappeared. Because of this high uptake in the leucocytes correction for even a small contamination with leucocytes of a platelet sample may be necessary.

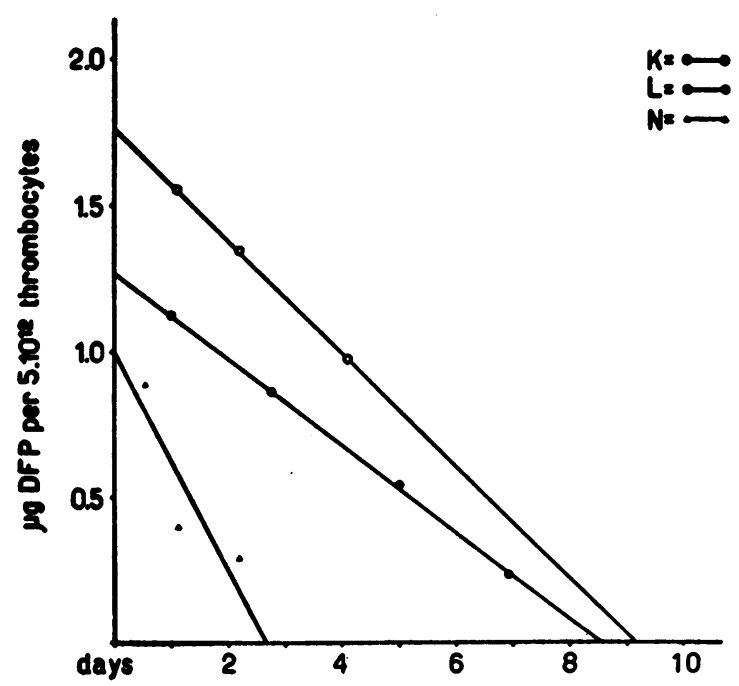

Fig. 3. Platelet-Bound Radioactivity after the INJECTION OF DFP

Activity expressed in $\mu \mathrm{g}$. of DFP per $5 \times 10^{12}$ platelets in the blood of subjects $K, L$, and $N$.

$\mathrm{K}$ male; 47 years; persistent thrombocytosis after splenectomy.

L female; 63 years; thrombocytopenic purpura due to gold, in remission after ACTH treatment.

$\mathrm{N}$ male; 77 years; polycythemia vera, splenomegaly, thrombopenia (platelet count about 90,000 per $\mathrm{mm}$. blood), some megakaryocytic hyperplasia in the bone marrow. 
The values obtained in patient $\mathrm{E}$ (chronic myeloid leukemia) and patient $F$ (polycythemia vera) suggest that in these two cases, both with a thrombocytosis and without splenomegaly, the survival time of the platelets did not differ from normal.

Owing to a technical error the results of platelet-bound radioactivity in patient $\mathrm{G}$ can only be given per $\mathrm{Gm}$. of $\mathrm{N}$.

Quite different were the results obtained in the two patients ( $\mathrm{M}$ and $\mathrm{N}$ ) with polycythemia vera with low platelet counts (about 100,000 per $\mathrm{mm}^{3}$ ). In both patients a splenomegaly was prominent and examination of sternal marrow showed an increased number of megakaryocytes with normal platelet formation. In patient $M$ no platelet-bound radioactivity could be demonstrated one day after injection of $\mathrm{DFP}^{32}$, though there was a normal uptake of $\mathrm{DFP}^{32}$ in the erythrocytes.

The results obtained in patient $\mathrm{N}$ are presented in Figure 3. On the third day after injection no more platelet-bound radioactivity could be detected. The data obtained in these two patients suggest a shortened life span of the platelets.

Figure 3 also includes data obtained on patients $\mathrm{K}$ and $\mathrm{L}$; both these cases were of special interest. Patient L had suffered from a severe thrombocytopenic purpura due to gold treatment. She was in complete remission after ACTH therapy. The peripheral platelet counts during the time of the experiment were maintained at about 250,000 per mm. ${ }^{3}$ The data obtained indicate that no abnormal breakdown of the platelets was taking place.

Patient $\mathrm{K}$ had undergone a splenectomy for an enlarged spleen two and a half years before admission. At operation he was found to have a very large infarcted spleen. Histological examination showed an increase in fibrous tissue. The splenectomy was followed by a persistant thrombocytosis associated with thrombotic and hemorrhagic manifestations. Sternal marrow examination revealed a cellular marrow with numerous megakaryocytes showing abundant platelet formation. The data obtained in this splenectomized patient suggest that the removal of the formed platelets from the blood was proceeding at a normal rate.

Results of the measurements of platelet bound radioactivity in the two postoperative patients $I$ and $\mathrm{H}$ are presented in Figure 4.

The interpretation of these curves with regard

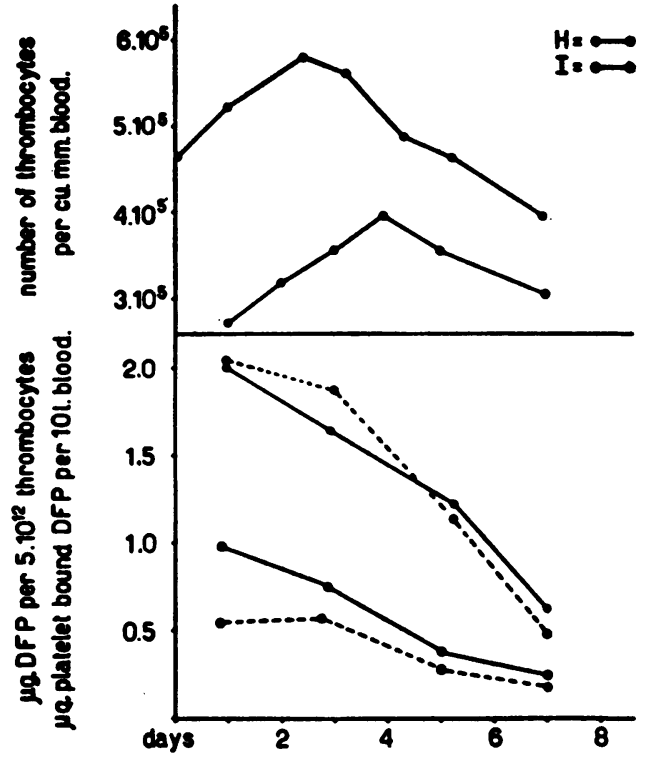

Fig. 4. The Upper Graph Presents the Values for the Platelet Counts in the Blood of Subjects $\mathrm{H}$ AND I

Platelet counts were performed in duplicate using calibrated pipettes according to the method of Feissly and Lüdin (19).

The Lower Graph Presents Values of PlateletBound Radioactivity AFTER INJECTION OF DFP ${ }^{28}$ IN THE BLoOd of Subjects H ANd I

Activity expressed in $\mu \mathrm{g}$. of DFP per $5 \times 10^{22}$ platelets (solid lines) and in $\mu \mathrm{g}$. of platelet-bound DFP per $10 \mathrm{~L}$. blood (broken lines).

$\mathrm{H}$ female; 57 years; cholelithiasis; DFP injected 8 days after cholecystectomy; postoperative course uneventful.

I male; 49 years, fracture of the femur head; DFP injected 8 days after nailing operation. Postoperative course uneventful.

to life span is difficult for reasons which will be elaborated in the discussion.

\section{DISCUSSION}

The results obtained demonstrate that DFP is bound to platelets. Expressed per $\mathrm{Gm}$. of nitrogen the amount of platelet-bound radioactivity is somewhat lower than the amout of radioactivity bound to the erythrocytes. In Table II comparative figures of the uptake of $\mathrm{DFP}^{32}$ in erythrocytes, platelets and leucocytes 6 and 24 hours after injection are given. Measurement of platelet-bound radioactivity will be most reliable during the first days after injection. In order to obtain an uptake of radioactivity high enough to permit meas- 
TABLE II

Uptake of DFPs in $\mu g$. per Gm. $N$ in platelets, erythrocytes and leucocytes

\begin{tabular}{|c|c|c|c|c|}
\hline Patients & $\begin{array}{c}\text { Hours } \\
\text { after } \\
\text { injection }\end{array}$ & Hemolysate & Platelets & Leucocytes \\
\hline $\begin{array}{l}\mathbf{A} \\
\mathbf{B} \\
\mathbf{D} \\
\mathbf{E} \\
\mathbf{G}\end{array}$ & $\begin{array}{r}24 \\
6 \\
6 \\
6 \\
6\end{array}$ & $\begin{array}{l}1.52 \\
1.34 \\
1.06 \\
2.20 \\
2.36\end{array}$ & $\begin{array}{l}0.68 \\
1.11 \\
0.53 \\
1.90 \\
1.25\end{array}$ & $\begin{array}{l}1.08 \\
1.32 \\
4.50 \\
3.50\end{array}$ \\
\hline
\end{tabular}

urement during a time of sufficient length for the determination of life span, DFP of high specific activity (about 200 microcuries per mg. DFP) has to be used. The amount of $\mathrm{DFP}^{32}$ that can be safely administered is restricted by the toxicity of DFP and the radiation hazard for the patient. In a normal person a dose of $1 \mathrm{mg}$. DFP containing 200 microcuries $\mathrm{P}^{32}$ per $\mathrm{mg}$. is enough to obtain platelet samples with a radioactivity of about ten times the background during several days after injection. The dosages, used by us, are entirely safe in both respects.

There is no reason to assume that the resorption of DFP from the muscular depots will last much longer than a few hours after the injection. Firstly, the maximum radioactivity in the total blood is reached in one and a half hours after the injection. Secondly, the excretion of DFP ${ }^{82}$ during the first 24 hours after the injection amounts to about 30 per cent of the administered dose ; in the same time about 20 per cent has been bound by the erythrocytes. This means that urinary excretion and binding to the erythrocytes account for at least 50 per cent of the injected dose within 24 hours. The results do not suggest that there has been an important delivery of marked cells from the bone marrow. Large variations in the radioactivity and in the amount of DFP administered prevailed throughout our experiments, without affecting the figures obtained for the life span. This suggests that radiation or toxic effects do not seriously interfere with the life span of the platelets under our conditions.

The method has proved useful in the determination of the life span of platelets in hematologically normal subjects. It was found to amount to 8 to 9 days. The same normal values were found in several patients suffering from various hematologic disorders with normal and high platelet counts. It is obvious that the method, involving platelet labelling in vivo, will be most satisfactory at normal or increased platelet values. In thrombopenic states the low availability of platelets that can be labelled might limit the applicability. In two cases of polycythemia vera with thrombopenia (patients $M$ and $N$ ), significantly shortened life spans were observed. In patient $M$ strong evidence also existed that the life span of the erythrocytes was markedly reduced; there was a persistent reticulocytosis, a high hemolytic index, and a life span of the erythrocytes determined with DFP $^{32}$ of about seventy days. In these two patients with thrombocytopenia, determination of the life span of the thrombocytes was made easier because the thrombocytopenia was not so severe and the blood cell volume was high making it possible to take a large blood sample for the isolation of the platelets.

The possibility that alteration of platelet material involving a modified reaction with DFP might lead to incorrect interpretation of the life span values should be considered.

It has been suggested (18) that in cases of polycythemia vera the finding of a normal platelet count might be due to increased production of platelets compensated by a shortened survival of these elements. The present method could be useful in elucidating this condition.

Results suggestive of a normal survival were obtained in two postoperative patients ( $\mathrm{H}$ and $\mathrm{I}$ ). However the interpretation of the data obtained (Figure 4) is complicated. First, the total thrombocyte count is not maintained at a stable level owing to the postoperative rise in platelet production. To obtain curves which would still faithfully express the rate of platelet breakdown it has been necessary to plot the radioactivity per volume of blood instead of per number of platelets (Figure 4). The same factor results in an uneven distribution of platelets among the various age groups with a resultant unequal rate of elimination. This would change the pattern in such a way that the later part of the curve would tend to have a steeper slope than the initial portion. The present curves might possibly be interpreted as showing the pattern to be expected on the basis of a normal survival time. However, additional data are required to justify the conclusion that the platelets enjoy a normal survival under these conditions. Any attempt to interpret postoperative platelet curves must be based on the knowledge of the life span of the platelets under these circumstances. 


\section{SUM MARY}

The uptake of $\mathrm{DFP}^{32}$ by the platelets was determined in 5 subjects without hematologic abnormalities, in 6 patients with hematologic abnormalities and in two postoperative patients. Results of the determination of platelet-bound radioactivity during several days after the injection of $\mathrm{DFP}^{32}$ are presented. A linear relationship between time and platelet-bound radioactivity was found indicating a measurable life span of these elements under normal circumstances. The slope of the curves obtained suggested that the life span amounts to about 8 to 9 days. In two patients suffering from chronic myeloid leukemia and polycythemia vera, respectively, both with thrombocytosis a normal survival time of the platelets was found. The data obtained on two patients with polycythemia vera with low platelet counts strongly suggested a considerable decrease of the life span of the platelets. Estimations carried out on two patients during the second week following an operation, though difficult to interpret owing to a fluctuating platelet count, are not inconsistent with a normal life span of the platelets under these conditions.

\section{ACKNOWLEDGMENT}

Our thanks are due to Professor Dr. A. Querido, for making his facilities available.

\section{REFERENCES}

1. Leeksma, C. H. W., and Cohen, J. A., Determination of the life of human blood platelets using labelled diisopropylfluorophosphonate. Nature, 1955, 175, 552.

2. Dillard, G. H. L., Brecher, G., and Cronkite, E. P., Separation, concentration and transfusion of platelets. Proc. Soc. Exper. Biol. \& Med., 1951, 78, 796.

3. Hirsch, E. O., and Gardner, F. H., The transfusion of human blood platelets with a note on the transfusion of granulocytes. J. Lab. \& Clin. Med., 1952, $39,556$.

4. Gardner, F. H., Howell, D., and Hirsch, E. O., Platelet transfusions utilizing plastic equipment. J. Lab. \& Clin. Med., 1954, 43, 196.

5. Hirsch, E. O., Gardner, F. H., and Thomas, E. D., Isolation and concentration of human blood platelets: Their properties in vitro and in vivo. J. Clin. Invest., 1952, 31, 638.

6. Stefanini, M., Chatterjea, J. B., Dameshek, W., Zannos, L., and Santiago, E. P., Studies on platelets II. The effect of transfusion of platelet-rich polycythemic blood on the platelets and hemostatic function in "idiopathic" and "secondary" thrombocytopenic purpura. Blood, 1952, 7, 53.

7. Odell, T. T., Jr., Gamble, F. N., and Furth, J., Life span of naturally labelled platelets of rats. Federation Proc., 1953, 12, 398.

8. Morgan, M. C., Keating, R. P., and Reisner, E. H., Jr., Labeling of rabbit platelets with iodine ${ }^{121}$. Proc. Soc. Exper. Biol. \& Med., 1954, 85, 420.

9. Mueller, J. F., Pathologic physiology of mammalian blood platelet utilizing $\mathrm{P}^{2 x}$ tagged rabbit platelets. Proc. Soc. Exper. Biol. \& Med., 1953, 83, 557.

10. Robertson, J. S., Milne, W. L., and Cohn, S. H., Labelling and tracing rat blood platelets with Chromium-51 in Radio Isotope Conference, 1954, Proceedings of the Second Conference, New York, Academic Press, Vol. 1, p. 205.

11. Julliard, J., Maupin, B., Loverdo, A., Bernard, J., Colvez, P., et Leconte, M., Premiers essais de transfusion a l'homme de leucocytes et de plaquettes marqués au radiophosphore. Presse méd., 1952, 60, 518.

12. Desai, R. G., Small, W., and Mednicoff, I., Studies on the survival and metabolic activity of platelets in humans, utilizing radio-active phosphorus. J. Clin. Invest., 1955, 34, 930.

13. Odell, T. T., Jr., Tausche, F. G., and Furth, J., Platelet life span as measured by transfusion of isotopically labelled platelets into rats. Acta $\mathrm{He}$ mat., 1955, 13, 45.

14. Morgan, M. C., Keating, R. P., and Reisner, E. H., Jr., Survival of radio-chromate-labeled platelets in rabbits. J. Lab. \& Clin. Med., 1955, 46, 521.

15. Cohen, J. A., and Warringa, M. G. P. J., The fate of $P^{20}$ labelled diisopropylfluorophosphonate in the human body and its use as a labelling agent in the study of the turnover of blood plasma and red cells. J. Clin. Invest., 1954, 33, 459.

16. Alexander, B., Some biochemical, physiological and pathological aspects of the coagulation mechanism in Blood Cells and Plasma Proteins, Their State in Nature, Tullis, J. L., Ed., New York, Academic Press, 1953, p. 78.

17. Oosterbaan, R. A., van Rotterdam, J., and Kunst, P., Synthesis of diisopropylphosphorofluoridate labelled with ${ }^{* P}$ (DF"P). Report Med. Biol. Lab. Nat. Def. Res. Council T.N.O. No. 31 (November 1955). 1

18. Black, M. M., Preston, J. A., and Speer, F. D., Histochemical and quantitative studies of the in vitro dehydrogenase activity of spleen in hypersplenism. Blood, 1955, 10, 145.

19. Feissly, R., et Lüdin, H., Microscopie par contrastes de phases (III. Applications à l'hématologie). Rev. d'hémat., 1949, 4, 481.

1 The method described in this report will appear shortly in more detail in the generally available literature. In the meantime a limited number of copies will be made available to workers in the field on application to Dr. J. A. Cohen. 